\title{
Conditions of Oral Health in Gastroplasty Obese Patients: Brief Comments
}

\author{
Gabriela Correa Biliato ${ }^{1}$, Noemi dos Santos Monteiro ${ }^{1}$, Cinthia de Souza Nazareth ${ }^{1}$, Idiberto \\ Jose Zotarelli Filho ${ }^{2 *}$, Diego Cesar Marques ${ }^{2}$, Leandro Moreira Tempest ${ }^{1,2}$ and Patricia Garani \\ Fernandes $^{1,2}$ \\ ${ }^{1}$ University Center North Paulista (Unorp) - Sao Jose do Rio Preto - SP, Brazil. \\ ${ }^{2}$ Post graduate and continuing education (Unipos), Street Ipiranga, 3460, Sao Jose does Rio Preto SP, Brazil.
}

Received: July 27, 2017; Accepted: August 8, 2017; Published: September 10, 2017

*Corresponding author: Idiberto Jose Zotarelli Filho, Unipos - Post graduate and continuing education, Street Ipiranga, 3460, Sao Jose do Rio Preto SP, Brazil 15020-040. Tel: +55(17) 98166-6537 / +55(17) 98803-7459; E-mail: m.zotarelli@gmail.com

\begin{abstract}
Background: One intervention that has been effective in treating obesity is bariatric surgery in a procedure in which it controls obesity through restriction and / or malabsorption of ingested foods.
\end{abstract}

Objective: The aim of the present study was to describe the oral condition in obese patients and after bariatric surgery.

Methods: A bibliographic survey was performed with 12 articles, searched through the PubMed virtual library. The search criteria were: 1) -present direct or indirect relationship of bariatric surgery with the words cited above. 2) - Regarding the period of publication: between 2011 and 2017. 3) - As to the language: Portuguese and English.

Conclusion: According to the main literary findings, there was a strong correlation between obesity and / or bariatric surgery with decreased oral health.

Keywords: Oral Health; Obesity; Bariatric surgery;

\section{Introduction}

The World Health Organization defines obesity as a chronic, noncommunicable disease characterized by the accumulation of adipose tissue; it can be a gateway to diseases potentially harmful to the health and well-being of the individual [1]. As an example, type 2 diabetes mellitus, heart problems (arteriosclerosis, arterial hypertension), sleep apnea and complications in joints even social problems due to self esteem, especially in women as a result of the body pattern exposed by current society [2].

About 300 million people have clinical obesity in all age groups and economic partner groups. One intervention that has been effective in the treatment of obesity is bariatric surgery in a procedure in which it controls obesity through restriction and / or malabsorption of ingested foods [3,4]. There are 3 techniques of bariatric surgery: 1) Bypass, also known as Roux / Fobi-Capella Y, which consists of Proximal Jejunal Anastomosis, is sectioned with the purpose of delimiting it, changing its capacity to 20 $\mathrm{ml}$, The remainder of the stomach, duodenum and the first $30 \mathrm{~cm}$ of the jejunum are excluded $[5,6]$.

According to Gonçalvez et al. One of the downsides of this surgery is a syndrome called dumping, dumping or emptying, causing nausea, vomiting, flushing, epigastric pain, hypoglycaemic symptoms [5]. Nutritional deficiencies are also found after bariatric surgery, due to restriction of food intake and / or reduction of absorption areas, according to Bordalo et al, there is a high prevalence of deficiency of Vitamin $\mathrm{B}^{12}, \mathrm{~A}$, $\mathrm{D}$ and $\mathrm{K}$, iron, folic acid, and also calcium, since Vitamin D helps in the absorption of calcium [2].

The link between dental caries and food intake is well demonstrated in the literature because of the role of sugars in their etiology. Obesityrelated eating habits may also determine a prevalence of caries making it clear that, obesity and caries may be in close contact due to the amount of sucrose ingested and the frequency of ingestion, in relation to periodontal disease, studies show that obesity presents as a risk factor due to proinflammatory cytokines by adipose tissue [4-12]. Therefore, the aim of the present study was to describe the oral condition in obese patients and after bariatric surgery.

\section{Methodology}

A bibliographic survey was carried out with 13 articles, searched through the virtual library PubMed - national library of medicine US, SciELO and Google academic. Key words were searched to perform the search: oral health, periodontal disease, bone loss, cavities, nutritional deficiency and reflux with emphasis on bariatric surgery - obesity. The search criteria were: 1) -present direct or indirect relationship of bariatric surgery with the words cited above. 2) - Regarding the period of publication: between 2011 and 2017. 3) - As to the language: Portuguese and English. The total number of papers - theses were 13, of which 7 were bibliographic reviews and 5 were surveys - questionnaires and a Randomized Controlled Trial (RCT). After selecting the studies, the two reviewers evaluated the selected studies to obtain the necessary information (sample studied, type of study, indices used and the main results).

\section{Brief Comments and Discussion}

\section{Bariatric Surgery / Obesity as a Risk Factor for Oral Health}

The interrelationship between obesity and oral health has been the 
subject of several articles, due to the increase of this disease in the current society. Moura-Grec et al, emphasize the importance of integrating the role of the dental surgeon into the multi professional team that treat obese and gastroplastized patients [7]. Generally patients undergoing Rouxen-Y gastric bypass surgery tend to suffer from chronic regurgitation or gastroesophageal reflux, which may be due to the narrowing of the silicone ring or to increased hypotonia of the lower esophageal sphincter, which leads to damage In the oral cavity, causing erosions in the enamel, with this dentin hypersensitivity, even erosions in the oral mucosa $[7,11,12]$.

Thus, bisphosphonates, osteoclastinhibitorydrugs, andare prescribed for patients who present some imbalance in the bone metabolism that promotes bone resorption, as in the treatment of osteoporosis, according to Bordalo et al, calcium deficiency has been found in the long term in patients who have undergone bariatric surgery, such as osteomalacia, hyperparathyroidism and osteoporosis, but osteonecrosis has been proven in patients who use bisphosphonates, and so the attention of the Dentist surgeon in anamnesis is of utmost importance [2].

\section{Conclusion}

According to the main literary findings, there was a strong correlation between obesity and / or bariatric surgery with decreased oral health.

\section{References}

1. Barbosa CS, Barberio GS, Marques VR, Baldo VO, Buzalaf MAR, Magalhaes AC. Dental Manifestations and Bariatric Patients: Literature Review. J Appl Oral Sci. 2009;17:1-4. doi: 10.1590/S1678-77572009000700002

2. Bordalo LA, Mourao DM, Bressan J. Nutritional Deficiencies After Bariatric Surgery: Why They Occur. Acta Med Port. 2011;24(4):1021-1028.

3. Borges LP, Terezan MLF, Bittencourt MSP. Obesity as a risk factor for periodontal disease. Braz J Periodontal. 2013;23(2):33-38.

4. Brianezzi LFF, Prestes LA, Andreatta LM, Vasconcelos LRM, Marsicano JA, Sales-Peres A, et al. Impact of obesity on oral health. Rev. OdontoBauru. 2013;18(2):211-216.

5. Goncalves EE, Souza DME, Carvalho RAR, Teixeira EC, Moura junior LG, Lima, DLF. Oral health condition of gatroplastized patients. Revista Periodontia. 2010;20(4):56-60.

6. Morais AB, Gasparetto A, Lolli MCGDS, Lolli LF. Bariatric surgery and factors related to oral health. Brazilian Journal of Surgery And Clinical Research. 2013;5(1):05-13.

7. Moura-Grec PG, Assis VH, Cannabrava VP, Vieira VM, Siqueira TL, Anaguizawa $\mathrm{WH}$, et al. Systemic consequences of bariatric surgery and its repercussions on oral health. Arq Bras Cir Dig. 2012;25(3):173-177.

8. Pataro AL, Cortelli SC, Abreu MHNG, Cortelli JS, Franco GCN, Aquino DR, et al. Frequency of periodontal pathogens and helicobacter pylori in the mouths and stomachs of obese subjects submitted to bariatric surgery: a cross-sectional study. J Appl Oral Sci. 2016;24(3):229-238. doi:10.1590/1678-775720150534

9. Peralta FS, Cortelli SC, Miranda TB, Nogueira LMR, Cortelli JR. Evaluation of the efficacy of non-surgical periodontal therapy in obese individuals: Review of the literature. Braz J Periodontol. 2016;26(1):49-56.

10.Porcelli ICS, Braga MP, Corsi NM, Poli-Frederico RC, Maciel SM. Prevalence of dental caries and its relationship with nutritional conditions among schoolchildren of a municipality in the south of Brazil. Clinica e Pesquisa em Odontologia. 2016;8(1).

11.Mustafa S. Bariatric surgery and bone loss. Internacional Juornal Of Nutrology. 2014;30(22):22-30.

12.Santos CF, Dias RB, Naves RC, Cavalcanti AN, RideiroEDP. Evaluation of oral conditions in obese patients. Revista Bahiana de Odontologia. 2014;5(2):8493. 